\title{
DESIGN, FABRICATION AND OPTIMIZATION OF OPERATIONAL PARAMETERS OF A SMALL SCALE DE- FEATHERING MACHINE
}

\author{
Oniya, O.O ${ }^{1}$, Akinlotan, O.A ${ }^{2}$, Abiodun, I.L ${ }^{3}$, Opadijo, $\mathrm{O}^{4}$. and Adebayo, A.O . $^{5}$ \\ ${ }^{12345}$ Department of Agricultural Engineering, \\ Ladoke Akintola University of Technology, \\ P.M.B. 4000, Ogbomoso, Nigeria.
}

\begin{abstract}
The aim of this work is to design and fabricate a small scale de-feathering machine and investigate into the optimal operational parameters for de-feathering. The fabricated de-feathering machine has its electric motor placed by its side for easy coupling, detachability and prolonged life span of motor. It has a door by its side for easy removal of the carcass. The materials used for the fabrication of the de-feathering machine were carefully selected to ensure minimal damage to the carcass. The optimal scalding temperature of $60{ }^{\circ} \mathrm{C}$, scalding time of 56.56 seconds, and de-feathering time of 12 seconds was found to have the highest efficiency of $96.6 \%$. The machine was able to achieve the desired quality. It saves time and it is of high efficiency.
\end{abstract}

Keywords: DESIGN, FABRICATION AND OPTIMIZATION, DEFEATHERING MACHINE

DOI: $10.7176 /$ ISDE/12-3-04

Publication date:September $30^{\text {th }} 2021$

\subsection{Introduction}

The increasing demand of animal protein necessitated the increase in supply of poultry birds. A better and faster way of removing feathers from poultry birds is important to meet this challenge. A de-feathering machine is an automated machine made for plucking the feathers off poultry, and it is usually used in poultry processing to defeather dead birds. Most plucking machine units can process many types of poultry, though some may have trouble with heavier birds such as turkeys. A typical de-feathering machine consists of big round container, fingerlike rubbers which have a mild effect on the birds' skin and an electric motor which powers the system as noted by Adetola (2012).

Depending on the model and method, most de-feathering take from one to six minutes to completely pluck all the feathers off a bird. There are several different methods of de-feathering and the common methods include wet, dry and wax. The process is rarely soft and gentle; rather, the bird is thrown or spun with a lot of speed and force to best remove the feathers. While there is a lot of force applied, most plucking machine units do not harm the bird therefore, the skin and muscle tissue will be intact and only the feathers will be removed.

De-feathering machine is not that popular among Nigerian farmers due to the high cost of the machine, however, the machine is mainly used in large farms where poultry bird are produced and processed in large quantity. The energy audit of some poultry processing plants with specific survey of five different relevant unit operations revealed that scalding and de-feathering is the most energy intensive unit operation accounting for $44 \%$ of the total energy consumption in the processing (Jekayinfa, 2007).

Scalding has to be done before de-feathering of birds can be done. To avoid accidents and infections from poultry carcasses which may occur during some of the processing operations there is a need for reliable and efficient poultry processing devices according to Ralph (1980) and Scolt (2000). The aim of this project is to design and fabricate a small scale de-feathering machine and to investigate into the optimal operational parameters for de-feathering.

\subsection{Materials and Method}

De-feathering machine that was fabricated has its electric motor placed by its side for easy coupling and detachability and prolonged life span of the motor. It has a door by its side for easy removal of the carcass. The materials used includes sheet metals, iron, thick gauge, plucking finger bearings, shaft and flat bar. 


\subsection{Design consideration}

Factors considered in the design of the machine in order for it to be suitable for eatery and household use (e.g. cutleries, machine and kitchen tools) were safety, portability, low cost of production, production capacity, durability of fabrication materials, materials availability, ease of alteration, finishing, reliability and ease of operation). Angle iron was used to fabricate the frame of the de-feathering machine due to its wide availability. The shape and size of the de-feathering machine was also considered before selecting the material for the frame.

\subsection{Material selection}

The rubber finger was used because of its mild effect on the carcass and its resistance to corrosion or rust which might necessarily occur in the housing unit as a result of a simple air-water reaction (corrosive environment), heat produced from the chicken and effect of cyclic stress, respectively.

The de-feathering chamber was made of sheet metal because of light weight. V-grooved pulley was selected to provide the required speed ratio. The pulley was made of cast iron with good coefficient of friction and the bearings were selected based on the standard size.

\subsection{Design analysis}

The following design analysis was carried out before the fabrication of the machine:

\subsubsection{Determination of diameter of de-feathering chamber}

The lateral diameter of a bird was $60 \mathrm{~mm}$. The machine was designed to process three birds simultaneously. A clearance space of $50 \mathrm{~mm}$ was allowed for collection of feathers of bird. Factor of safety was also put into consideration. The needed diameter for the de-feathering chamber was calculated as follow:

$60 \mathrm{~mm} \times 3$ (birds) $+50 \mathrm{~mm}=230 \mathrm{~mm}$

The smallest available diameter of the disc was $460 \mathrm{~mm}$; therefore the chosen diameter was $460 \mathrm{~mm}$.

\subsubsection{Determination of space between the plucking bands}

The space between the bands was dependent on the material that was used. The shape of the defeathering chamber was cylindrical. This did not enhance the appropriate determination of the space of the plucking bands as of that on a flat surface. The space between the bands was also dependent on the size of the machine and number of birds' involved (Cunningham et al., 1994). The diameter of the plucking fingers was 22 $\mathrm{mm}$ as measured from the rubber fingers used.

\subsubsection{Determination of shaft power}

Shaft speed was designed to be $180 \mathrm{rpm}$ based on the findings of Oklahoma state university (1990). The shaft speed was $180 \mathrm{rpm}$ the torque transmitted to the machine was calculated as follows:

$$
\text { Power }=\frac{2 \times \pi \times T}{60}
$$

$$
\begin{aligned}
& \text { Where: } \\
& P=\text { Power, } \mathrm{kW} \\
& N=\text { speed, } \mathrm{rpm} \\
& T=\text { Twisting moments, N/m } \\
& P=1.5, \mathrm{~kW} \\
& n=180, \mathrm{rpm}
\end{aligned}
$$


$T=$ ?

$\pi=3.142$

$$
\begin{gathered}
T=\frac{60 \times P}{2 \times \pi \times \mathrm{N}} \\
\mathrm{T}=\frac{60 \times 1.5 \times 10^{3}}{2 \times 3.142 \times 180} \\
\mathrm{~T}=\frac{9000}{1131.12}
\end{gathered}
$$

$\mathrm{T}=79.57 \mathrm{~N} / \mathrm{m}$

\subsubsection{Selection of electric motor}

The available electric motors were $1 \mathrm{hp}, 2 \mathrm{hp}$ and $3 \mathrm{hp}$ during fabrication of the machine. The driver and driven rpm for $1 \mathrm{hp}$ was calculated as follows:

$$
\text { Velocity ratio }(V R)=\frac{N_{2}}{N_{1}}
$$

Where:

$N_{2}=$ speed of machine pulley

$N_{l}=$ speed of motor pulley

$$
V R=\frac{R_{2}}{R_{1}}
$$

Where:

$R_{2}=$ Radius of machine pulley

$R_{l}=$ Radius of electric motor pulley

The ratio of the motor's pulley radius to the machine's pulley radius was 15.6: 1 . The machine speed used was 175-180 rpm as stated by Oklahoma State University (1990).

\subsubsection{Determination of power required by the machine}

The power required by the machine was given by Khurmi and Gupta, 2006 and was calculated as follows:

$$
P=\left(T_{1}-T_{2}\right) V
$$

Where:

$P=$ expected power to be transmitted by the motor to the shaft though the belt in $\mathrm{kW}$

$V=$ speed of the belt, $\mathrm{m} / \mathrm{s}$

$T_{1}=$ belt tension on tight side, $\mathrm{N}$

$T_{2}=$ belt tension on slack side, $\mathrm{N}$

The Speed 'V' was given by Khurmi and Gupta, 2006 and was calculated as follows:

$$
V(m / s)=\frac{\pi d_{m N}}{60}
$$

Where:

$\pi=3.142$ 
$d_{m}=$ diameter of the motor pulley

$N=$ speed in rpm of the motor

$$
C_{w}=\frac{1}{e^{\theta}-1}
$$

Where:

$C_{W}=$ Belt power $\mathrm{kW}$

$\Theta=$ Angle of wrap rad

$\mathrm{e}=2.718$

$$
T_{e}=T_{1}-T_{2}
$$

Where:

$T_{e}=$ Effective belt tension

$T_{l}=$ Belt tension on the tight side, $\mathrm{N}$

$T_{2}=$ Belt tension on the slack side, $\mathrm{N}$

$$
T_{2}=\frac{\text { Belt power } K w}{\text { Belt speed } \mathrm{m} / \mathrm{s}}
$$

Where:

$$
\begin{aligned}
& C_{W}=\text { Belt power, } \mathrm{kW} \\
& V=\text { Belt speed, } \mathrm{m} / \mathrm{s}
\end{aligned}
$$

$$
T_{2}=C_{w} \times T_{e}
$$

Where:

$T_{2}=$ Belt tension on the slack side, $\mathrm{N}$

$C_{W}=$ Belt power $\mathrm{kW}$

$\mathrm{T}_{\mathrm{e}}=$ Effective belt tension, $\mathrm{N}$

$$
\theta=\theta_{b}=\pi+2 \times \sin ^{-1} \frac{R_{A} \mid R_{B}}{C}
$$

Where :

$$
\Theta=\theta_{b}=\text { Angle of wrap }
$$

$C=$ Distance between the centers of pulley A and pulley B

$R_{A}=$ Radius of driver pulley $\mathrm{A}$

$R_{B}=$ Radius of driven pulley B

\subsubsection{Determination of length of belt (Open)}

$$
L=\left(r_{2}+r_{1}\right)+2 X+\frac{\left(r_{2}-r_{1}\right)^{2}}{2 X}
$$

Where:

$r_{2}$ and $r_{1}$ are the radii of the large and small pulleys respectively

$\mathrm{X}$ is the distance between the two pulleys

\subsubsection{Torsional shear stress $\mathrm{N} / \mathrm{mm}$}

The Torsional shear stress was calculated as follows: 


$$
T=\frac{\pi \times \mathrm{t} \times \mathrm{d}^{3}}{16}
$$

Where:

$T=$ twisting moment

$t=$ Allowable shear stress

$d=$ diameter of shaft

$\pi=3.142$

\subsubsection{Round solid shaft}

The polar moment of inertia of the shaft about the axis of rotation was calculated as follows:

$$
I=\frac{\pi \times \mathrm{d}^{4}}{32}
$$

Where:

$J=$ Polar moment of inertia of the shaft about axis of rotation $\left(\mathrm{m}^{4}\right)$

$d=$ Diameter of the shaft

\subsubsection{Torsional moment $\left(M_{t}\right)$}

The Torsional moment was calculated as follows:

$$
M_{t}=\frac{\mathrm{P} \times 60}{2 \times \pi \times \mathrm{n}}
$$

Where:

$M_{t}=$ Torsional moment

$P=$ power of the electric motor

$n=$ machine required speed

\subsubsection{Factor of safety}

The factor of safety was calculated as follows:

$$
F . S=\frac{\text { Ultimate } \text { shear } \text { stress }}{\text { working } \text { stress }}
$$

Where:

Working stress $=$ Allowable shear stress $(\mathrm{t})$

Ultimate shear stress for mild steel (Swami 2002) $=42 \mathrm{MPa}$

\subsubsection{Efficiency}

The efficiency of the machine was calculated as follows:

$$
\text { Efficiency }=\frac{\mathrm{W}_{1} \times 100}{\mathrm{~W}_{1} \times \mathrm{W}_{2}}
$$

Where:

$W_{l}=$ Weight of feather removed by machine

$\mathrm{W}_{2}=$ Weight of feathers remaining on the bird thus: removed by hand.

V-grooved pulley was selected to provide the required speed ratio. The pulley was made of cast iron with good coefficient of friction and the bearings were selected based on the standard size. 


\subsection{Description of Machine}

The de-feathering machine was of dimension $460 \mathrm{~mm} \times 400 \mathrm{~mm} \times 900 \mathrm{~mm}$ as seen in the Appendix A \& $\mathrm{B}$, and Plate 1 . The body was in a cylindrical form with installed plucking finger while the basement which was the collector of feathers and shaft was made of mild steel because the material was found most suitable due to its availability, low cost, light weight and other favorable mechanical, chemical and thermal properties.

The de-feathering mechanism consisted of a rotating disc and a de-feathering chamber (stationary) of 16 $\mathrm{mm}$ thickness, studded with a series of rubber fingers slotted horizontally to the side wall of the cylinder. The remaining space that existed between two adjacent rubber fingers forms the housing unit for the chicken where the operation were been performed, the carcass rest on the disc which rotate the carcass of the bird and this action made the carcass have several contacts with the rubbers on the wall of the de-feathering chamber.

The machine was in three identifiable assemblies with their functional components. The power transmission units as the name implied was the source of force for rotating the shaft connected to the disc. The housing units comprise the frame cover, the de-feathering chamber, de-feathering chamber support, bolt and nut, plucking fingers and bearing. The basement unit was the base and its main function was to collect the feather and pass to the outlets.

\subsection{Performance evaluation and analysis}

However, three birds were used for the trial and test running of the machine and also to get familiar with the process before the final analysis was carried out. An electric motor was fastened to the fabricated defeathering machine and a v-belt was attached to it. A thermometer was used to monitor the temperature of the water to ensure it was not above or below the required temperature.

A lagged container was used to minimize the loss of heat during the process. The de-feathering time was monitored using the stop watch and the weighing scale was used to check for the mass of the feathers removed and the feathers left on the carcass of the bird. The de-feathering process started with the manual feeding of bird whose feathers are to be plucked by the machine. The chicken was soaked in hot water (T) for some minutes $(T S)$ depending on the type of bird (exotic) after the process called scalding, the bird was lowered into the de-feathering machine which first rest on the disc. Plate 2 shows the carcass of the bird before defeathering and after defeathering.

The bird was dropped down into the de-feathering mechanism which was made of metal sheet lined internally with rubber fingers which was subjected into a rotary motion by the transmitted torque from the electric motor. The carcass was rubbed with rubber fingers and the feathers were thereby plucked continuously until the time $(T d)$ that the feather was completely plucked.

\subsection{Optimization of the de-feathering parameters}

Black exotic birds obtained from Ladoke Akintola University of Technology Research Farm, Ogbomoso, Nigeria was used for the analysis. Response surface methodology was used to optimize the defeathering process. The scalding time, scalding temperature and de-feathering time was optimized using Design expert software Version 6.08 as shown in the Table 1.

Efficiency of the machine was calculated as follows:

$$
\text { Efficiency }=\frac{\mathrm{W}_{1} \times 100}{\mathrm{~W}_{1} \times \mathrm{W}_{2}}
$$

Where:

$\mathrm{W}_{1}=$ Weight of feather removed by machine

$\mathrm{W}_{2}=$ Weight of feathers remaining on the bird thus: removed by hand. 


\subsection{Results and Discussions}

The result for optimization of de-feathering machine, (Soft scalding, $53{ }^{\circ} \mathrm{C}$ to $60{ }^{\circ} \mathrm{C}$ ) is shown in Table 2. The average scalding temperature was $60{ }^{\circ} \mathrm{C}$, scalding time was 60 seconds, de-feathering time was 12 seconds and the efficiency was $94.7 \%$ but according to the optimization performed by Hung (2008), which had a scalding temperature of $60{ }^{\circ} \mathrm{C}$, scalding time of 55 seconds and de-feathering time of 22 seconds and an efficiency of $92.4 \%$. This is also similar to the result obtained by Adetola (2012).

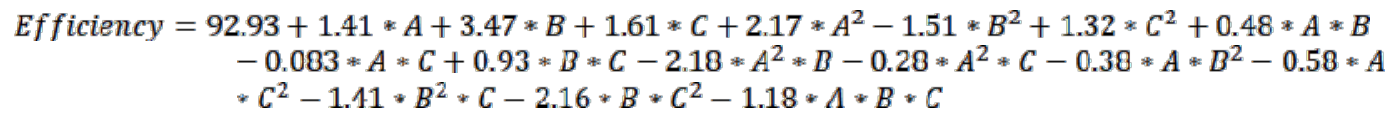

From the graph of efficiency against de-feathering time and scalding time at a scalding temperature of $60{ }^{0} \mathrm{C}$ (figure 2), it was noticed that the efficiency increases and then decreases while the scalding time increases. It was also observed that as the de-feathering time increases, efficiency decreases and then got to a point where it starts to increase. From Figure 3, as scalding time increases efficiency decreases and then increases. Figure 4 shows the graph of efficiency against de-feathering time and scalding temperature at a scalding time of 56.50 second. As the de-feathering time and scalding temperature increases, the efficiency increased.

\subsection{Conclusions}

The de-feathering machine was able to achieve the desired result. It was simple to operate and also efficient. It therefore serves as a substitute for the manual method of removing feathers from poultry birds. Therefore from the results obtained of scalding temperature $60{ }^{\circ} \mathrm{C}$, scalding time of 56.56 seconds, and defeathering time of 12 seconds was found to have the highest efficiency of $96.6 \%$

\section{REFERENCES}

Adetola (2012). Investigation into mechanized de-feathering process and optimal scalding temperature of exotic and local birds in southern Nigeria. African Journal of Agricultural Research Vol. 7(11), pp. 1607-1622. Retrieved on $19^{\text {th }}$ March, 2012. Available online at http://www.academicjournals.org/AJAR

Bilgili, S.F. (2002). Poultry products and processing in the international market place uburn Department of Mechanical Engineering, Faculty of Engineering, Vinh Long University, DOI: 10.5897/AJAR10.079 ISSN 1991-637X (C) 2012 Academic Journals

Glenn, J. (1998) Mechanical harvesting of broilers. Poultry Sci. 77:1794 Ho Chi MinhCity, VIET NAM DongNai Science and Technology Department, VIET NAM Hochiminh city (in Vietnamese). Summary Report of the Project supported by Ministry of Education and Training. 84 pages.

Hung, N. V. (2003). Analysis and technological rationalization of poultry processing lines. Ph.D thesis. University of Agriculture in Nitra, Slovakia. 170 pages.

Hung, N.V. 2006. Reseach on Improving of small scale systems of poultry processing in Hung, N.V. 2010. Reseach on improving techonology and equipment of small scale poultry Hung, N.V. and Kovac, S. 2003. Design of poultry processing line 500 birds per hour for 
Hung, N.V. and Rao. (2008). Numerical methods and Applied Matlab in Engineering (in Vietnamese). International Transaction Journal of Engineering, Management, Applied Sciences \& Technologies. 1991-637X (C) 2012 Academic Journals.

Table 1: Optimization parameters for de-feathering

\begin{tabular}{|c|c|c|c|c|c|}
\hline & & & Factor 1 & Factor 2 & Factor 3 \\
\hline Std & Run & Block & $\begin{array}{l}\text { A:Scalding temp } \\
\left({ }^{\circ} \mathrm{C}\right)\end{array}$ & $\begin{array}{l}\text { B:Scalding time } \\
(\mathrm{sec})\end{array}$ & $\begin{array}{l}\text { C:De-feathering time } \\
(\mathrm{sec})\end{array}$ \\
\hline 28 & 1 & Block 1 & 60 & 56.5 & 12 \\
\hline 3 & 2 & Block 1 & 61 & 54 & 11 \\
\hline 13 & 3 & Block 1 & 59 & 56.5 & 12 \\
\hline 1 & 4 & Block 1 & 59 & 54 & 11 \\
\hline 10 & 5 & Block 1 & 59 & 54 & 12 \\
\hline 14 & 6 & Block 1 & 60 & 56.5 & 12 \\
\hline 5 & 7 & Block 1 & 60 & 56.5 & 11 \\
\hline 18 & 8 & Block 1 & 61 & 59 & 12 \\
\hline 15 & 9 & Block 1 & 61 & 56.5 & 12 \\
\hline 23 & 10 & Block 1 & 60 & 56.5 & 13 \\
\hline 19 & 11 & Block 1 & 59 & 54 & 13 \\
\hline 32 & 12 & Block 1 & 60 & 56.5 & 12 \\
\hline 31 & 13 & Block 1 & 60 & 56.5 & 12 \\
\hline 17 & 14 & Block 1 & 60 & 59 & 12 \\
\hline 7 & 15 & Block 1 & 59 & 59 & 11 \\
\hline 20 & 16 & Block 1 & 60 & 54 & 13 \\
\hline 26 & 17 & Block 1 & 60 & 59 & 13 \\
\hline 21 & 18 & Block 1 & 61 & 54 & 13 \\
\hline 29 & 19 & Block 1 & 60 & 56.5 & 12 \\
\hline 16 & 20 & Block 1 & 59 & 59 & 12 \\
\hline 11 & 21 & Block 1 & 60 & 54 & 12 \\
\hline 9 & 22 & Block 1 & 61 & 59 & 11 \\
\hline 2 & 23 & Block 1 & 60 & 54 & 11 \\
\hline 24 & 24 & Block 1 & 61 & 56.5 & 13 \\
\hline 4 & 25 & Block 1 & 59 & 56.5 & 11 \\
\hline 22 & 26 & Block 1 & 59 & 56.5 & 13 \\
\hline 6 & 27 & Block 1 & 61 & 56.5 & 11 \\
\hline 25 & 28 & Block 1 & 59 & 59 & 13 \\
\hline 12 & 29 & Block 1 & 61 & 54 & 12 \\
\hline 27 & 30 & Block 1 & 61 & 59 & 13 \\
\hline 30 & 31 & Block 1 & 60 & 56.5 & 12 \\
\hline 8 & 32 & Block 1 & 60 & 59 & 11 \\
\hline
\end{tabular}




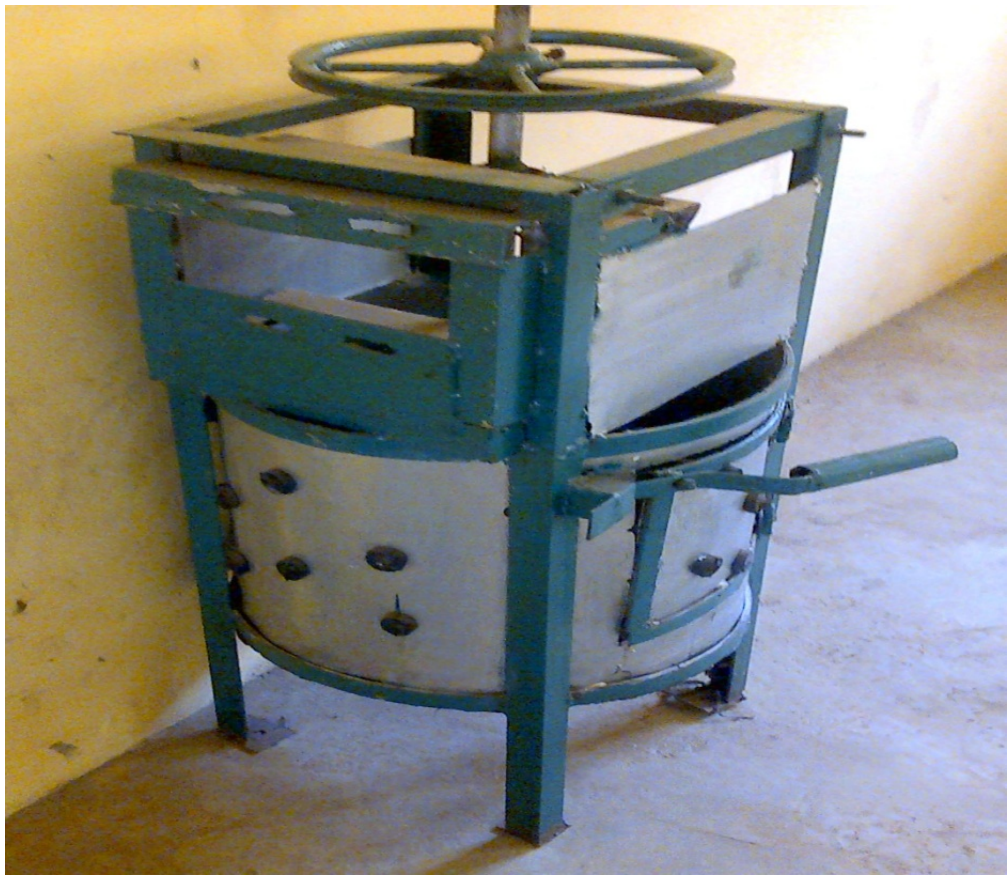

Plate 1: De-feathering machine

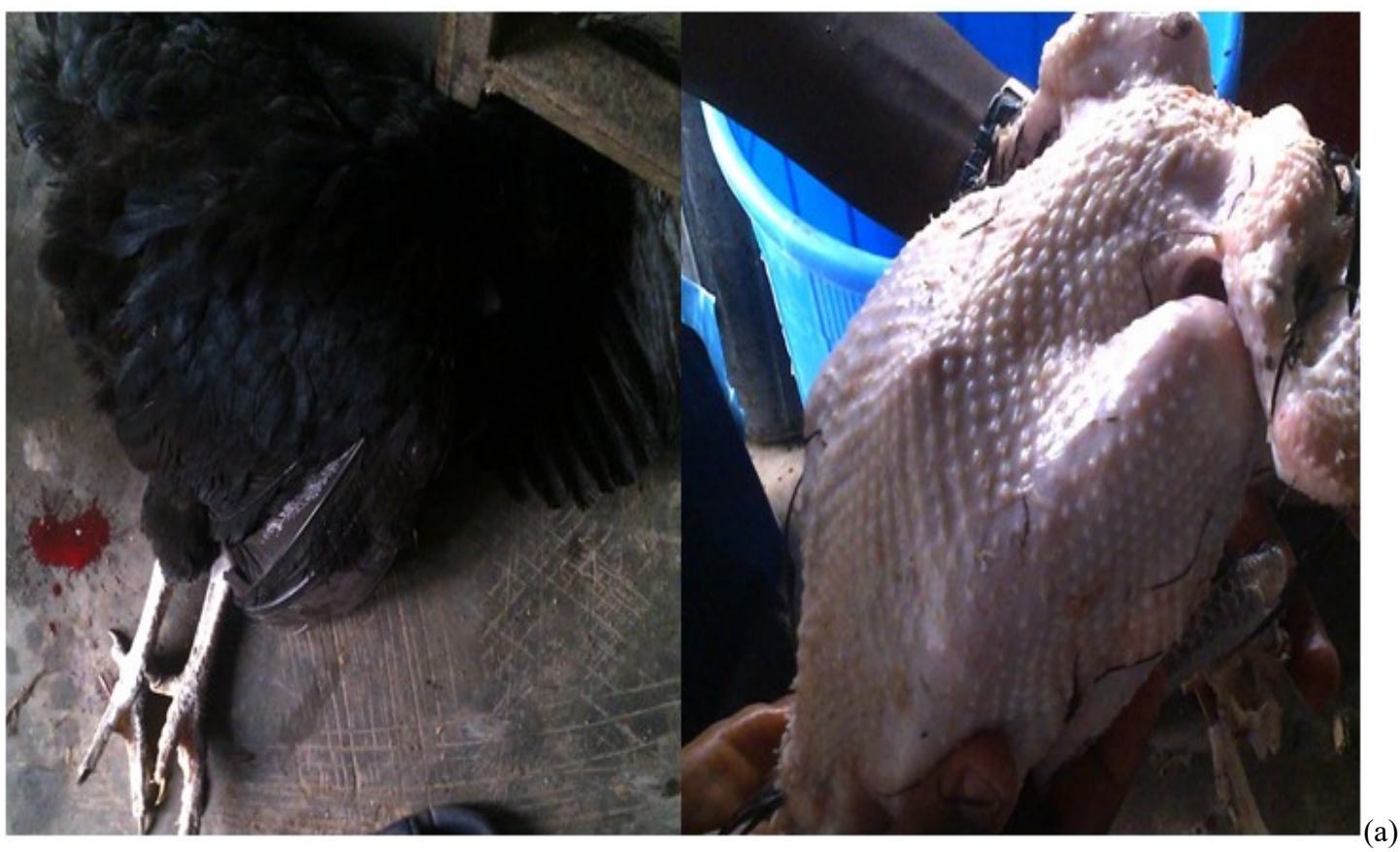

(b)

Plate 2 (a): Bird before defeathering

(b): Bird after defeathering 

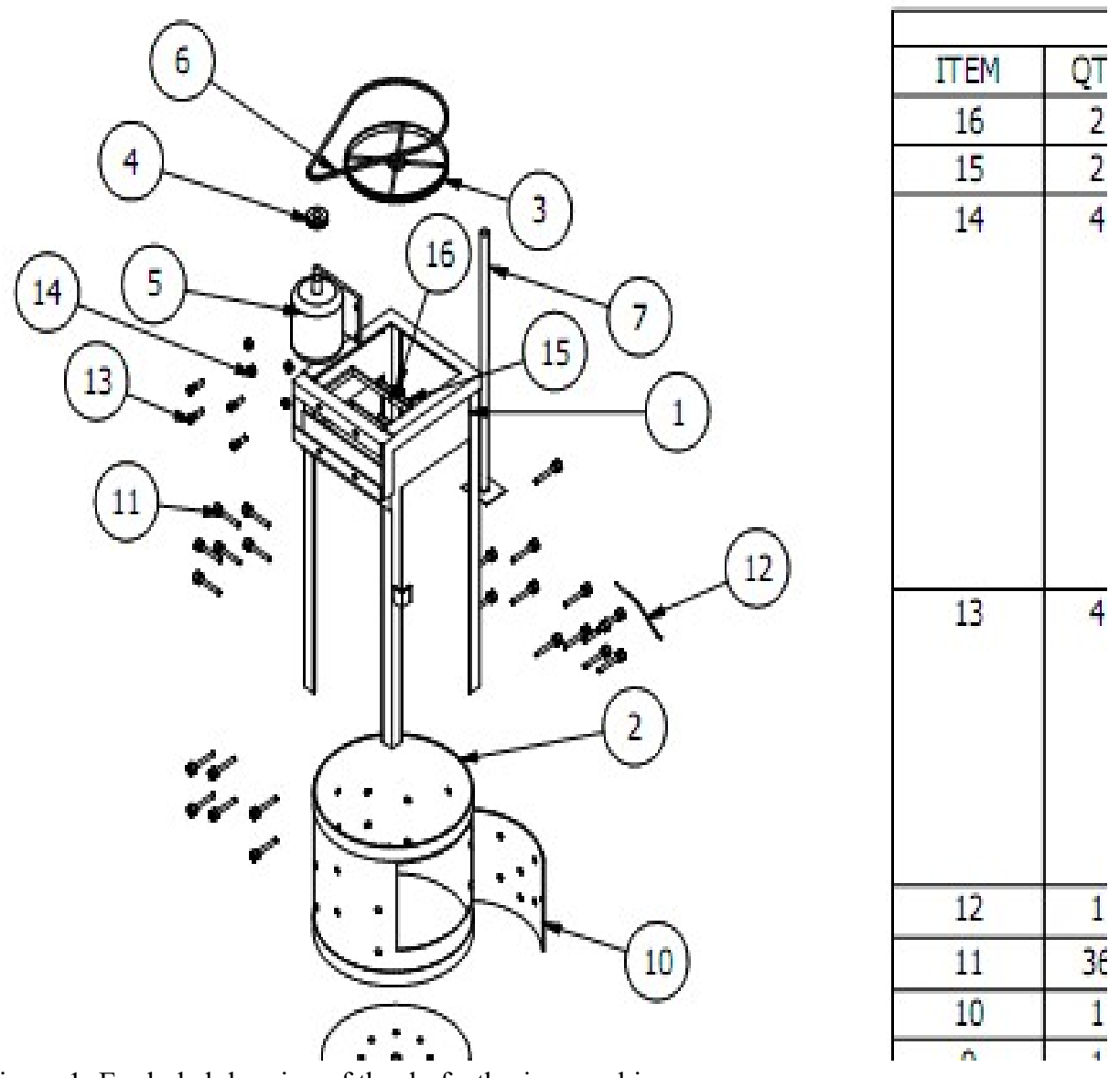

Figure 1: Exploded drawing of the de-feathering machine

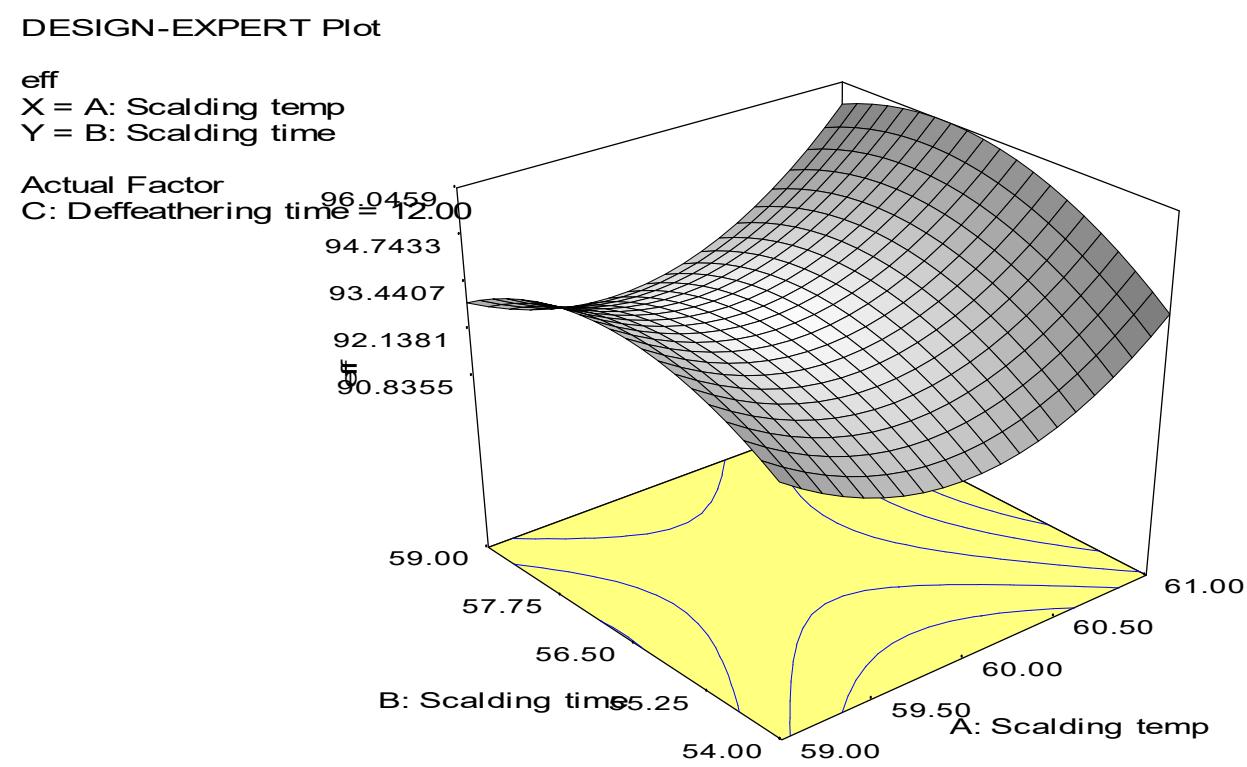

Figure 2: Graph of Efficiency against de-feathering time and Scalding time at a scalding temperature of $60^{\circ} \mathrm{C}$ 
Table 2: Optimization of de-feathering parameters using response surface methodology

\begin{tabular}{|c|c|c|c|c|c|c|}
\hline & & & Factor 1 & Factor 2 & Factor 3 & Response \\
\hline Std & Run & Block & $\begin{array}{l}\text { A:Scalding } \\
\text { temp } \\
{ }^{0} \mathrm{C}\end{array}$ & $\begin{array}{l}\text { B:Scalding time } \\
\text { Sec }\end{array}$ & $\begin{array}{l}\text { C:Deffeathering time } \\
\text { Sec }\end{array}$ & $\begin{array}{l}\text { Efficiency } \\
\%\end{array}$ \\
\hline 28 & 1 & Block 1 & 60 & 56.5 & 12 & 94.4 \\
\hline 3 & 2 & Block 1 & 61 & 54 & 11 & 95 \\
\hline 13 & 3 & Block 1 & 59 & 56.5 & 12 & 91.5 \\
\hline 1 & 4 & Block 1 & 59 & 54 & 11 & 96.2 \\
\hline 10 & 5 & Block 1 & 59 & 54 & 12 & 96.2 \\
\hline 14 & 6 & Block 1 & 60 & 56.5 & 12 & 92.9 \\
\hline 5 & 7 & Block 1 & 60 & 56.5 & 11 & 91.9 \\
\hline 18 & 8 & Block 1 & 61 & 59 & 12 & 96.2 \\
\hline 15 & 9 & Block 1 & 61 & 56.5 & 12 & 96.6 \\
\hline 23 & 10 & Block 1 & 60 & 56.5 & 13 & 96.2 \\
\hline 19 & 11 & Block 1 & 59 & 54 & 13 & 92.9 \\
\hline 32 & 12 & Block 1 & 60 & 56.5 & 12 & 95.4 \\
\hline 31 & 13 & Block 1 & 60 & 56.5 & 12 & 96.6 \\
\hline 17 & 14 & Block 1 & 60 & 59 & 12 & 92.3 \\
\hline 7 & 15 & Block 1 & 59 & 59 & 11 & 92.3 \\
\hline 20 & 16 & Block 1 & 60 & 54 & 13 & 92.6 \\
\hline 26 & 17 & Block 1 & 60 & 59 & 13 & 95 \\
\hline 21 & 18 & Block 1 & 61 & 54 & 13 & 96.2 \\
\hline 29 & 19 & Block 1 & 60 & 56.5 & 12 & 92.9 \\
\hline 16 & 20 & Block 1 & 59 & 59 & 12 & 93.2 \\
\hline 11 & 21 & Block 1 & 60 & 54 & 12 & 78.4 \\
\hline 9 & 22 & Block 1 & 61 & 59 & 11 & 96.6 \\
\hline 2 & 23 & Block 1 & 60 & 54 & 11 & 96 \\
\hline 24 & 24 & Block 1 & 61 & 56.5 & 13 & 96.2 \\
\hline 4 & 25 & Block 1 & 59 & 56.5 & 11 & 93.6 \\
\hline 22 & 26 & Block 1 & 59 & 56.5 & 13 & 96 \\
\hline 6 & 27 & Block 1 & 61 & 56.5 & 11 & 94.4 \\
\hline 25 & 28 & Block 1 & 59 & 59 & 13 & 96 \\
\hline 12 & 29 & Block 1 & 61 & 54 & 12 & 95 \\
\hline 27 & 30 & Block 1 & 61 & 59 & 13 & 95.4 \\
\hline 30 & 31 & Block 1 & 60 & 56.5 & 12 & 94.4 \\
\hline 8 & 32 & Block 1 & 60 & 59 & 11 & 91.9 \\
\hline
\end{tabular}




\section{DESIGN-EXPERT Plot}

eff

$X=B$ : Scalding time

$\mathrm{Y}=\mathrm{C}$ : Deffeathering time

Actual Factor

A: Scalding temp $=95: 1832$

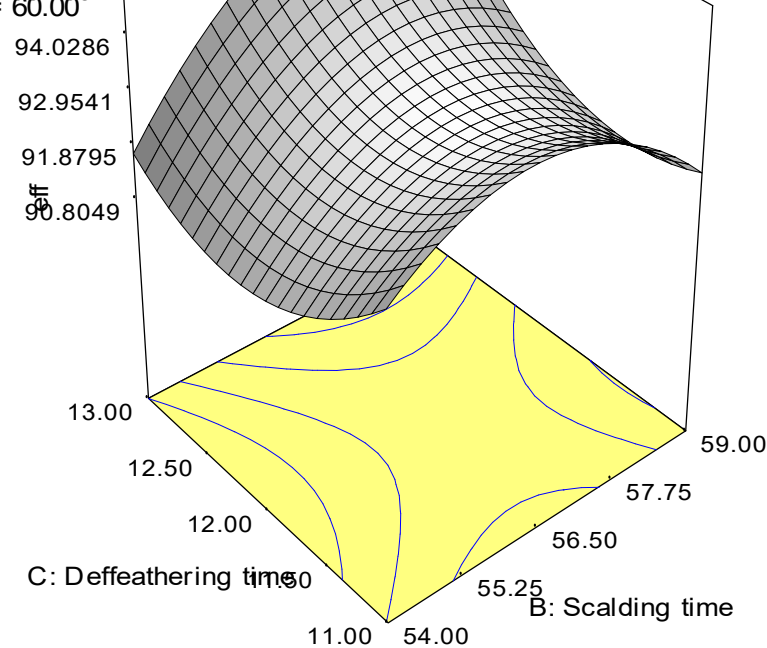

Figure 3: Graph of Efficiency against Scalding time and scalding temperature at de-feathering time of 12 seconds 


\section{DESIGN-EXPERT Plot}

eff

$X=A:$ Scalding temp

$\mathrm{Y}=\mathrm{C}$ : Deffeathering time

Actual Factor

B: Scalding time $=56.50^{71}$

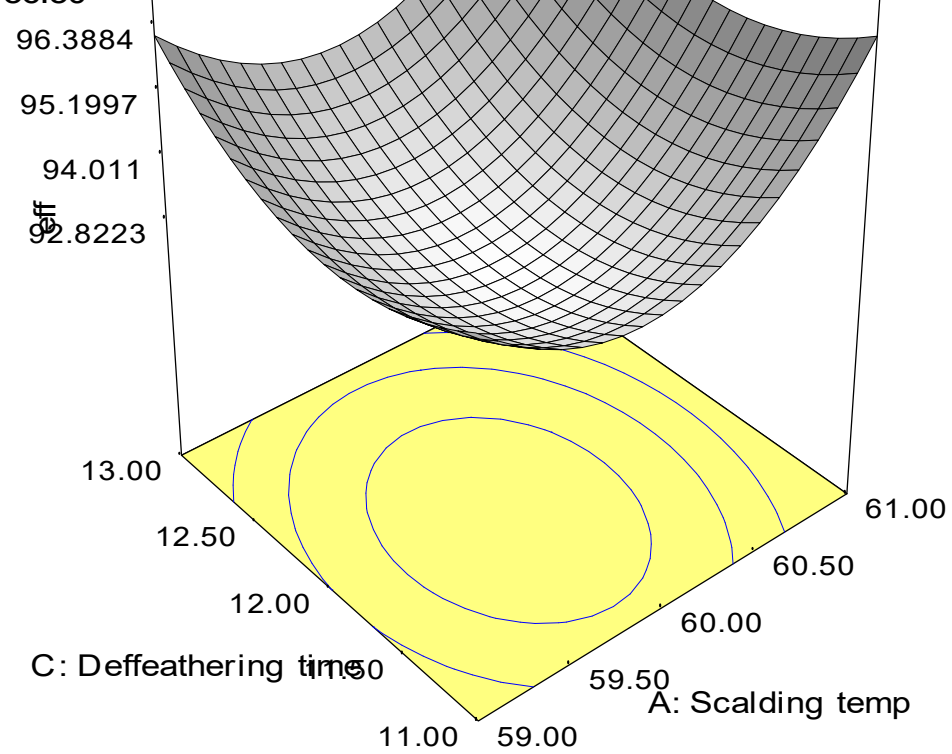

Figure 4: Graph of Efficiency against de-feathering time and Scalding temperature at a scalding time of 56.50 second 